\title{
Cork - a natural material for linalool controlled release
}

\author{
Sara Sousa, Mário Silva, Filipa Oliveira Gomes, \\ Valentina Maria Fernandes Domingues, Cristina Delerue Matos
}

\begin{abstract}
Controlled release of aromatic mixtures to the atmosphere is a requirement for scented systems for indoor applications. The product must smell nice, but also be able to last, slowly releasing the perfume over time. Several adsorption materials have been used, for this purpose. In this study, cork was investigated as a potential perfume adsorbent for application in scented drawer sachets and equivalent products. Cork was selected due to its adsorption properties and because it is a natural, renewable, sustainable material. Granulated cork is a significant by-product in cork industries and it was chosen for adsorption in this work. Linalool, an enantiomeric monoterpene alcohol and one of the main components of several essential oils, was selected as the model compound for adsorption studies.

Activated carbon (AC) was used as the reference material. The sorption of linalool to granulated cork and AC was evaluated by HS-SPME-GC-FID. The linalool isotherm on cork was shown to follow a Brunauer-Deming-Deming and Teller, Type IV model. The isotherm data on AC can be adjusted to Langmuir and Freundlich models. A maximum adsorption capacity of $3.9 \times 10^{3} \mu \mathrm{g} / \mathrm{g}$ was achieved for AC. Desorption studies were performed. Linalool was still released from granulated cork after three equilibrium stages of desorption, whereas only two desorption values were obtained for AC from the equilibrium with highest linalool concentration. Thus, AC demonstrated good adsorption but not good desorption properties. Sorption and desorption studies of linalool from granulated cork, showed that granulated cork could be an excellent material allowing controlled release of the aroma.
\end{abstract}

\section{KEYWORDS}

\section{Controlled aroma release, cork, HS-SPME, linalool, sorption}

\section{INTRODUCTION}

Lavenders are popular aromatic plants; the genus Lavandula (Lavender) includes more than 30 species, dozens of subspecies, and hundreds of hybrids and selected cultivars. The oils of these plants are usually used as food additives, in cosmetics, hygiene products and traditional medicines. ${ }^{1,2}$ One of the main components of lavender species is linalool. This is also the main component of the majority of essential oils (EOs). ${ }^{3}$

Abbreviations used: AC, activated carbon; BDDT, Brunauer, Deming, Deming and Teller; EOs, essential oils; FID, flame ionization detector; GAC, granular activated carbon; GC, gas chromatography; HS-SPME, headspace solid-phase

microextraction; LOD, limit of detection; LOQ, limit of quantification; MS,

mass spectrometry; PAC, powdered activated carbon; PEA, 2-phenylethanol; PLA, Polylactic acid
EOs, like linalool, have been used in bacterial, insecticidal, medicinal and cosmetic applications since the 1950's. ${ }^{4}$ Around 12,000 tons of linalool are produced per year worldwide from both natural extraction and chemical synthesis. Most of the synthetic linalool (95\%) is used as a fragrance ingredient in cosmetic products, such as perfumes and body lotions, and in non-cosmetics, like household cleaners and waxes.

Only $1 \%$ is used in food and beverages for aroma and flavour, such as tea, specifically black, dark, oolong and green tea. ${ }^{5-7}$

Besides the applications already described, EOs with linalool, have been used through history in traditional medicine, to relieve symptoms and cure a variety of both acute and chronic ailments. ${ }^{8,9}$ Many EOs have the ability to relieve stress and reduce anxiety. 10

In addition to all previous applications, consumers enjoy fragrance delivery materials, from scented paper to washed textile fabrics and so on. As a result, there is a significant need for fragrance delivery 
systems that can provide long-lasting fragrance release. Usually substrates are treated by spraying, coating or dipping in a fragrance, however, the fragrance is lost over time to the environment. The most

common solution is the use of encapsulates. ${ }^{11}$ Although this technique can protect and prevent the loss of fragrance as well as improve the release and stability of the core materials, ${ }^{12}$ the encapsulates are expensive and complex to prepare. ${ }^{11}$ The development of delivery sys- tems using natural polymers ${ }^{13}$ offers distinct advantages, such as bio- compatibility, biodegradability, and cost effectiveness. As a response to demand, industries are constantly trying to develop aroma delivery systems and to discover new materials that allow the desired effects. The means of effectively releasing volatile compounds often requires development of new delivery systems. ${ }^{14}$ In fact, there are several patents ${ }^{11,15-18}$ on essential oils release for indoor and closet use. Cork is a natural, renewable, sustainable raw material that has been used for many centuries as natural cork stoppers, insulation boards, production of cork/rubber composites for shoe soles, memo boards, gifts and panels and agglomerates for wall and floor coverings. ${ }^{19}$ The main sector of the cork industry remains the production of natural cork stoppers. ${ }^{20}$ Among different applications, cork was shown to be a good and low cost material for adsorption processes. ${ }^{21,22}$ The chemical constitution of cork depends on various factors such as geographic origin, climate and soil conditions, genetic origin, tree dimensions, age and growth conditions. $^{19}$ The cellular structure of cork is alveolar, similarto a honeycomb shape, without empty spaces between adjoining cells (closed units). This closed cells structure, made mostly of suberin,

is responsible for cork's impermeability to liquids and gases. ${ }^{19}$

In this work, cork was used as sorbent for linalool as the model compound. To the author's knowledge, no other studies of sorption capacity of cork to fragrances have been performed. A commercial activated carbon (AC) was included as a standard sorbent for comparison. AC remains one of the most important microporous adsorbent. ${ }^{23}$ ACs are the oldest adsorbents known, widely applied, ${ }^{24,25}$ extensively used on an industrial scaleas an adsorbentto purify/separate liquids and gases or as a catalyst. $^{24}$

For the analysis of linalool, Headspace Solid Phase Microextration (HS-SPME) coupled with gas chromatography (GC) with flame ionization detector (FID) was used. HS-SPME is a simple, fast, and solventfree analytical technology and has been widely used in the analysis of volatile compounds. ${ }^{6,26}$ It is an efficient and sensitive method for extraction and pre-concentration of target analytes, widely used in a broad range of applications due to organic solvent avoidance and interferences elimination. ${ }^{27}$ HS-SPME has been coupled with gas chro- matography (GC), with tandem mass spectrometry (MS), and applied to

analyse EO's directly evaporated from leaves and to quantify linalool in teas. The success of its use depends on several factors such as chemical nature of the compounds to be extracted, temperature used during extraction and extraction time. ${ }^{28,29}$ In order to maintain precision and reproducibility, those factors must be kept constant. ${ }^{29}$

The goal of this work was to characterise linalool adsorption and desorption properties of granulated cork in order to evaluate its potential as a non-energized volatile material delivery system for controlled release of linalool and essential oils to indoor air. Also, in this work sorption and desorption of linalool in cork was compared to $A C$ as a reference material. Adsorption and desorption processes were carried out using the standard batch equilibrium method. The granulated cork used in this work is an industrial waste and its grain size is more suitable to be applied in hand-made scented package however with less potential to other applications.

\section{EXPERIMENTAL}

All reagents used were analytical grade: Linalool ( $\geq 95 \%)$ from Fluka Sigma-Aldrich ${ }^{\circ}$ Chemie GmbH (St. Louis, MI, USA) and methanol from VWR Chemicals Prolabo® (Fontenay-sous-Bois, France). SPME fibres polydimethylsiloxane/divinylbenzene (PDMS/DVB, $65 \mu \mathrm{m}$ ) and holder for manual sampling were purchased from Supelco® (Bellefonte, PA, USA). AC (1240 PLUS) was obtained from Norit N.V. This carbon was selected because it is an acid washed Granular AC, which offers good adsorption properties and a high purity level. According to the supplier's specifications, it has a neutral $\mathrm{pH}$ and a particle size between 0.5 and $1.5 \mathrm{~mm}$.

Prior to industrial uses, cork planks are boiled in water for approximately $1 \mathrm{~h}$, this process being repeated with other planks in the same boiling water for 2 to 4 days, depending on the cork processing plant. Granulated cork (from cork stoppers waste production), with a diameter (d) of $1<\mathrm{d}<2 \mathrm{~mm}$, was supplied by the company Amorim \& Irmãos, S. A., Santa Maria de Lamas, Portugal. Beside initial treatment with boiling water, to remove excess powder, the granulated material was washed with deionized water and dried at $60 \pm 5^{\circ} \mathrm{C}$ for 4 days.

\subsection{Procedure}

For all procedures, each sorption result from a specific time or concentration was obtained in different individual flasks, because the SPME sampling should only be performed once per flask. To the entire experiments, the gas phase was analysed using HS-SPME-GC-FID.

Considering the scope of this study (characterizing the sorption/

desorption of linalool in selected adsorbents) several parameters should be optimized. The suitable exposition time of HS-SPME was accessed by measuring the obtained area in different times of exposure and in different flasks ( $1 \mathrm{~L}$ volumetric flasks) with the same concentration of linalool. The lowest exposition time which presented the maximum area of chromatographic peak, was established as the HS-SPME suitable exposition time.

Standard solutions of linalool were prepared between 0.108 and $207.6 \mu \mathrm{g} / \mathrm{L}$ in methanol.

\subsection{Calibration curve}

Besides the HS-SPME exposition time (equilibrium between SPME and $\mathrm{HS}$ ) also the time to which linalool needs to reach equilibrium in the system (closed flask), was necessary to be accessed. In order to establish this last equilibrium time, a set of flasks were prepared with $10 \mu \mathrm{L}$ of the same standard solution and closed with rubber stoppers coated with parafilm. The real available volume of each flask was determined by measuring the amount of water between the single ground-in graduation mark and the top (real available volume ranged between $1.025 \mathrm{~L}-1.047 \mathrm{~L}$ ).

The flasks were incubated at $22 \pm 0.1^{\circ} \mathrm{C}$ in a Liebherr model FKU 1800 incubator and the concentration of linalool was measured (two replicates) at different times (time range from 2-32 hours). The 
equilibrium time was determined when linalool achieved a constant area (the linalool reached in equilibrium in the HS).

After establishing the equilibrium time, the calibration curve was performed. Another set of flasks was prepared, three replicates of each concentration in a total of ten standards (total of thirty flasks were prepared). The incubation conditions previously described were maintained and the chromatographic peak area for each flask was measured by HS-SPME-GC-FID.

\subsection{Kinetic studies}

Although the equilibrium time was determined previously, it is necessary to make sure that this time was enough for the equilibrium to be achieved also in the studies involving the chosen sorbents (cork and $\mathrm{AC}$ ). And so, kinetic studies were performed in the same manner that was previously described. A set of flasks was prepared with $10 \mu \mathrm{L}$ of the same standard solution and a known amount of sorbent (300 mg cork or $500 \mathrm{mg} \mathrm{AC).} \mathrm{The} \mathrm{flasks} \mathrm{were} \mathrm{closed} \mathrm{with} \mathrm{rubber}$ stoppers coated with parafilm and kept in a thermostatic shaking incubator at $22 \pm 0.1^{\circ} \mathrm{C}$ at constant stirring at $50 \mathrm{rpm}$. With the same approach, the concentration of linalool was measured (two replicates) at different times (time range from 2-44 hours). The equilibrium time was determined when linalool achieved a constant area.

\subsection{Adsorption studies}

Three replicates of each standard solution were prepared with the same amount of sorbent (with range 20-300 mg granulated cork or AC). The flasks were closed with rubber stoppers coated with parafilm and kept in an incubator at $22 \pm 0.1^{\circ} \mathrm{C}$ and constant stirring at $50 \mathrm{rpm}$, until the system reached equilibrium was previously established. After which the HS-SPME extraction was performed, also in the incubator, and the concentration of linalool in each flask was measured by

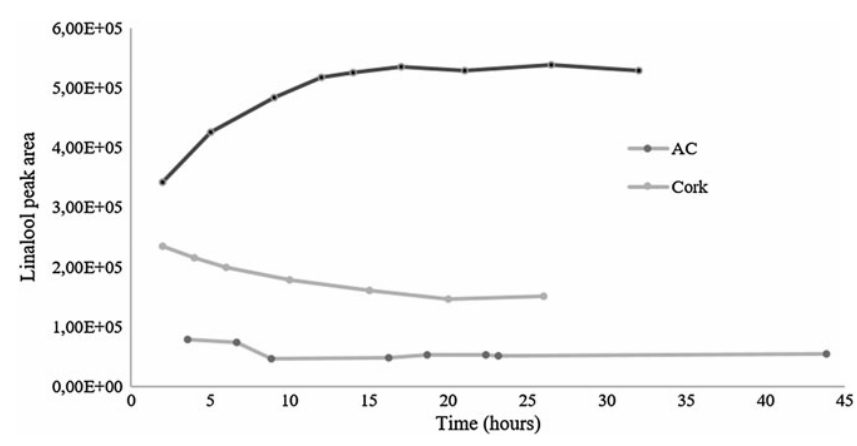

FIGURE 1 Kinetics studies of linalool on cork and AC
GC-FID. Two models were tested to describe adsorption in the AC studies - Langmuir and Freundlich. Using the Langmuir sorption isotherm, the equilibrium adsorption data could be described as:

$$
q^{1 / 4} \frac{K_{L} q_{m} C_{e q}}{1 p K G_{q}}
$$

or according to Freundlich sorption isotherm, as:

$$
q^{1 / 4} K F C_{e q}^{1}=n
$$

where $q$ is the adsorbed amount $(\mu \mathrm{g} / \mathrm{g}), \mathrm{C}_{\mathrm{eq}}$ the equilibrium concentration $(\mu \mathrm{g} / \mathrm{L}), \mathrm{K}_{\mathrm{L}}$ the Langmuir constant, $\mathrm{q}_{\mathrm{m}}$ the monolayer capacity, and $\mathrm{K}_{\mathrm{F}}$ is the adsorption constant that represents the degree or strength of adsorption, and the exponent $1 / n$ takes in account non-linearity in the adsorption isotherm.

The best-fitting curves through the experimental data were calculated by an Excel tool (solver), using Langmuir and Freundlich equations.

\subsection{Desorption studies}

After adsorption evaluation, cork or AC were immediately transferred to a new $1 \mathrm{~L}$, without any essence, and this incubation/analysis procedure was repeated several times. This process guarantees the release in a free linalool known volume. The flasks were kept, as before, in a thermostatic shaking incubator at $22 \pm 0.1^{\circ} \mathrm{C}$ and constant stirring at $50 \mathrm{rpm}$ (make note that the three replicates, for each standard and sorbent used in the adsorption studies were used to desorption studies). The amount of linalool, in each flask, was measured after the system reached equilibrium by HS-SPME-GC-FID. Three desorption isotherms were constructed with cork, although aroma was still detected through olfactometric measurements after the fourth desorption experiment. Desorption tests were carried out in this manner until the desorbed linalool presented values $<L O Q$ of the analytical method.

\subsection{Linalool analysis by gas chromatography sorption evaluation}

Prior to their first use, the SPME fibres were conditioned according to manufacturer's instructions. The analyses were carried out in a gas chromatograph system with a FID, Shimadzu GC-2010. Separation was performed on an Agilent ${ }^{\circledR} \mathrm{J} \& \mathrm{~W}$ CP-Sil 88 capillary column $(60 \mathrm{~m} \times 0.25 \mathrm{~mm}$ I.D., $0.20 \mu \mathrm{m})$ from Santa Clara, CA, USA. Like before, HS-SPME, the fibre was immediately inserted into the GC system injection port, after the extraction time, where the analytes were thermally desorbed from the fibre coating in the split mode. Operating conditions were as follows: the injector and detector temperatures

TABLE 1 Calibration data for linalool analysis

\begin{tabular}{rc} 
& FID Shimadzu GC- 2010 \\
\hline Retention time & $6.886 \mathrm{~min}$ \\
Range of linearity & $27.2-827.6 \mu \mathrm{g} / \mathrm{L}$ \\
Calibration curve & $\mathrm{Y}=758.93 \mathrm{C}+31875$ \\
$\mathrm{Y}=$ linalool area; & $\mathrm{C}=\mathrm{concentration}(\mu \mathrm{g} / \mathrm{L})$
\end{tabular}


were kept at $250^{\circ} \mathrm{C}$ and $270^{\circ} \mathrm{C}$, respectively; the temperature programme was as follows: initial temperature $60^{\circ} \mathrm{C}$ for $1 \mathrm{~min}$, increased at $20^{\circ} \mathrm{C} / \mathrm{min}$ to $215^{\circ} \mathrm{C}$ and held at this temperature for $3 \mathrm{~min}$ (total run time: $11.75 \mathrm{~min}$ ). The carrier gas was $\mathrm{He}, 30 \mathrm{~mL} / \mathrm{min}$ and the detector gas flows were: $\mathrm{H}_{2}, 40 \mathrm{~mL} / \mathrm{min}$ and air, $400 \mathrm{~mL}$ min. Data acquisition and processing were performed with Shimadzu software GCsolution for GC systems.

\section{3 | RESULTS AND DISCUSSION}

\section{1 | Extraction time}

A 20 min. of exposition time of HS-SPME was demonstrated suitable for the intended purpose. The established SPME exposition time at $22 \pm 0.1^{\circ} \mathrm{C}$ was maintained in all the experiments, ensuring the same conditions of extraction obtaining a relative standard deviation of $4.6 \%$.

\subsection{Equilibrium time}

After approximately $18 \mathrm{~h}$, no increase in the chromatographic peak area was observed to neither cork, AC nor without adsorbent, view Figure 1. Leading to the conclusion that linalool reached the equilibrium in $\mathrm{HS}$ and with both sorbents. The $18 \mathrm{~h}$ time was the established equilibrium time for all the experiments. For practicality, the determination of linalool's concentration in the gas phase was carried out after $20 \mathrm{~h}$ of contact time by HS-SPME-GC-FID analysis, to assure that the equilibrium was reached.

\subsection{Linalool quantification}

The parameters obtained for the calibration curve are presented in Table 1. For the sorption studies, the calibration curve was obtained with concentrations in the range 27.2-827.6 $\mu \mathrm{g} / \mathrm{L}$, which showed a linear correlation (retention time of 6.886 minutes). The limit of detection and limit of quantification were obtained considering the slope of the calibration line and the residual standard deviation of the regression line. ${ }^{30}$ The obtained LOD was $8.1 \mu \mathrm{g} / \mathrm{L}$.

\subsection{Adsorption isotherms}

The adsorption isotherms were identified according to the classification of Brunauer, Deming, Deming and Teller (BDDT) for the basic types of isotherms. ${ }^{31}$ The adsorption isotherm for cork (Figure 2 ) is a type IV isotherm, that represents adsorption isotherms with

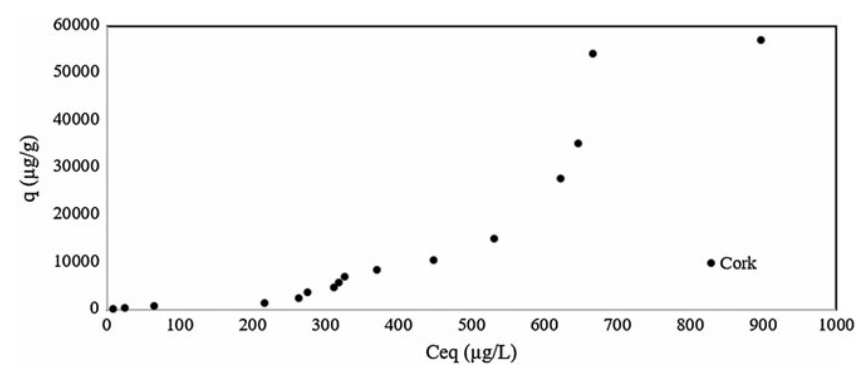

FIGURE 2 Linalool isotherms on cork hysteresis. ${ }^{32}$ The adsorption happens in layers. At lower gas concentrations the adsorption is monolayer and occurs primarily in all the available areas. ${ }^{31}$ Considering that Langmuir's theoretical model should not be applied to BDDT isotherms, $\mathrm{q}_{\mathrm{m}}$ was not calculated for granulated cork. However, Figure 2 shows a step of adsorption around 5.5 $\times 10^{4} \mu \mathrm{g} / \mathrm{g}$, which indicates probably the highest amount of linalool adsorbed.

The adsorption isotherm for AC (Figure 3), on the other hand, was identified as a type I isotherm. This isotherm occurs when the adsorption is limited to, at least, a few molecular layers and when microporous powders whose pore size does not exceed a few adsorbate molecular diameters. ${ }^{31}$ The Langmuir model proposes that adsorption process happens on a homogenous surface via monolayer sorption, with uniform energies of adsorption. ${ }^{22,33}$ The adjustment to the Langmuir model shows a $\mathrm{q}_{\mathrm{m}}$ of $3.9 \times 10^{3} \mu \mathrm{g} / \mathrm{g}$ and $\mathrm{k}_{\mathrm{L}}$ of $3.4 \times$ $10^{-2} \mathrm{~L} / \mu \mathrm{g}$ (Figure 3).

The Freundlich model suggests a monolayer sorption with a heterogeneous energetic distribution of active sites. ${ }^{22,33}$ The adjustment to the Freundlich model shows an $n$ of 2.8 and $k_{F}$ of $6.5 \times$ $10^{-6} \mathrm{~L} / \mu \mathrm{g}$ (Figure 3).

Another adsorption study of Lavandula angustifolia oil, specifically linalool, on sodium modified bentonite, performed by Miz et al. (2014) obtained $q_{m}$ and $k_{L}$ of $2.7 \times 10^{2} \mu \mathrm{g} / \mathrm{g}$ and $3.3 \times 10^{-1} \mathrm{~L} / \mu \mathrm{g}$, respectively, by Langmuir adjustment, and an $n$ of 0.4 and $k_{F}$ of $8.0 \times 10^{5} \mu \mathrm{g} / \mathrm{g}^{34}$ for the adjustment to the Freundlich model. In comparison with our study AC, obtained a higher value $\left(3.9 \times 10^{3} \mu \mathrm{g} / \mathrm{g}\right)$ for monolayer capacity.

\subsection{Balances of adsorption and desorption}

The calculations of adsorbed and desorbed linalool were based on the following equations ${ }^{22:}$

$1 / 2$ Initial amount] $1 / 41 / 2$ Free amount] $\mathrm{p}^{1 / 2}$ Adsorbed amount]

The adsorbed amount could be analysed as follows:

$$
\begin{aligned}
& 1 / 2 \text { Adsorbed amount }]^{1 / 4}{ }^{1 / 2 \text { Desorbed amount] }} \\
& \text { p }^{1 / 2 \text { Final adsorbed amount] }}
\end{aligned}
$$

Figure 4 shows the occurrence of hysteresis, which means that desorption happens slower than adsorption and is partially irreversible. The desorption of linalool will be slow and resistant, which proves that linalool can be continuously released, by aroma perception even after four equilibrium stages of desorption. For the experimental setup used in this study, submitting cork granules to a $\mathrm{C}_{\text {eq }}$ of $800 \mu \mathrm{g} / \mathrm{L}$, has shown

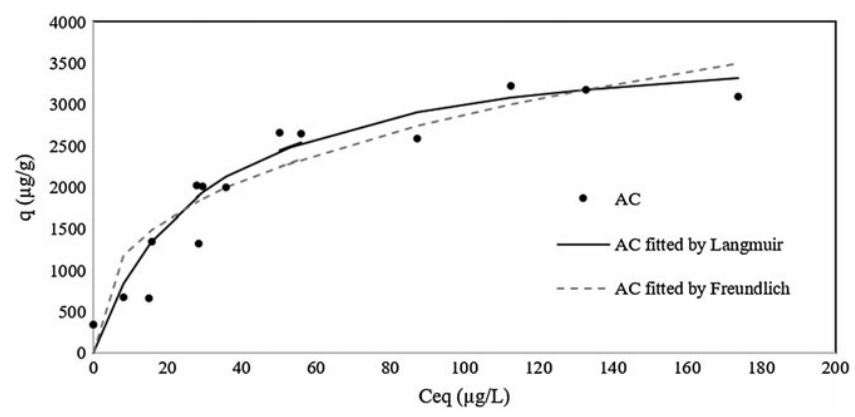

FIGURE 3 Linalool isotherms on AC, fitted by Langmuir and Freundlich models 
FIGURE 4 Adsorption and desorption isotherms of linalool on cork

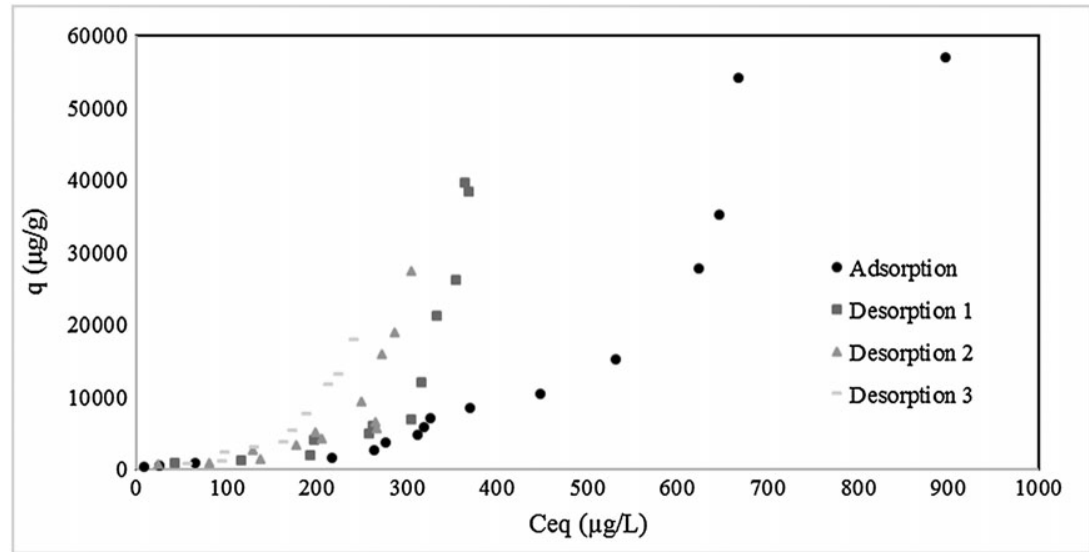

to achieve the best desorption performance and consequently extending fragrance release time.

According to the authors' knowledge, only another material (silica gel) was investigated for linalool desorption, by Reverchon et al.

(1997). A Langmuir-like equation provided the best representation of the experimental data; at 75 bar, the desorption isotherm was found to have a qm of $2.3 \times 10^{2} \mu \mathrm{g} / \mathrm{g}$ and a $\mathrm{kL}$ of $3.6 \mathrm{~L} / \mu \mathrm{g}$. However, a direct comparison to this work is not adequate, because Reverchon et al.'s study was performed at high pressure and at $40^{\circ} \mathrm{C},{ }^{35}$ whereas this work was done at atmospheric pressure and $22^{\circ} \mathrm{C}$.

Considering the cellular structure of cork that is analogous to honeycomb, with no empty spaces between contiguous cells, ${ }^{19}$ this structure will allow a slower desorption since the alveolar structure would be a reservoir of linalool.

The permeability of cork to water vapor is $110.1 \times 10^{-13} \mathrm{~mol} /(\mathrm{m} \mathrm{s}$ $\mathrm{Pa})^{36}$ (very low) with diffusion of water a considerably slow process, with diffusion coefficients of $1 \times 10^{-11}$ and $4 \times 10^{-10} \mathrm{~m}^{2} \mathrm{~s}^{-1}$ in the non-radial and radial directions. ${ }^{37}$ Therefore it can be assumed that humidity will not affect significantly the sorption process.

AC seems to be a good adsorbent, however, it is not adequate for fragrance release, as shown by the adsorption and desorption isotherms, respectively (Figure 5). Linalool was only detected in two desorption experiments, which had been exposed to the higher concentration of $\mathrm{C}_{\text {eq }}$ in adsorption phase, and just two equilibrium stages of desorption were obtained.

Since linalool is a well-known natural insecticide and larvicide the research for materials to release linalool is not a novelty. Souza et al. ${ }^{14}$ reports the release characteristics of linalool encapsulated at three concentrations in Polylactic acid (PLA) nanofibrous membranes, as well as the effect of linalool on fiber morphology and structural properties. Further development of PLA membranes encapsulated with linalool oil was considered useful, in creating commercial markets for PLA/linalool composite materials with potential applications in controlled-release devices. ${ }^{14}$

Another promising material is cashew gum, a polysaccharide extract from Anacardium occidentale, that has technological interest in delivery systems. Due to its rheological characteristics, biodegradability and being a raw natural material, sharing advantages with cork including low cost and low environmental impact. ${ }^{13,38}$ However, these materials have some drawbacks, like poor control rate of hydration, thickening, decrease of viscosity upon storage and microbial contamination susceptibility. ${ }^{39}$

The use of fragranced sachets is appreciated by many consumers and may be beneficial for human health, to be used in closets and cabinets. They have been demonstrated to have significant antibacterial, antifungal, antimycotic, antihelmintic and antiseptic properties. ${ }^{40}$

The present research proves the $\mathrm{AC}$ effectiveness as an adsorbent material for linalool, considering its good removal efficiency. Kinetic studies revealed that $18 \mathrm{~h}$ is adequate to achieve equilibrium for granulated cork and AC.

Equilibrium studies revealed favourable linalool adsorption at $22^{\circ} \mathrm{C}$ for both materials. Cork adsorption isotherm obtained is a type IV, showing hysteresis. A type I isotherm was obtained for AC and a $\mathrm{q}_{\mathrm{m}}$ of $3.9 \times 10^{3} \mathrm{\mu g} / \mathrm{g}$ was obtained as maximum adsorption capacity estimated by adjustment to the Langmuir model.

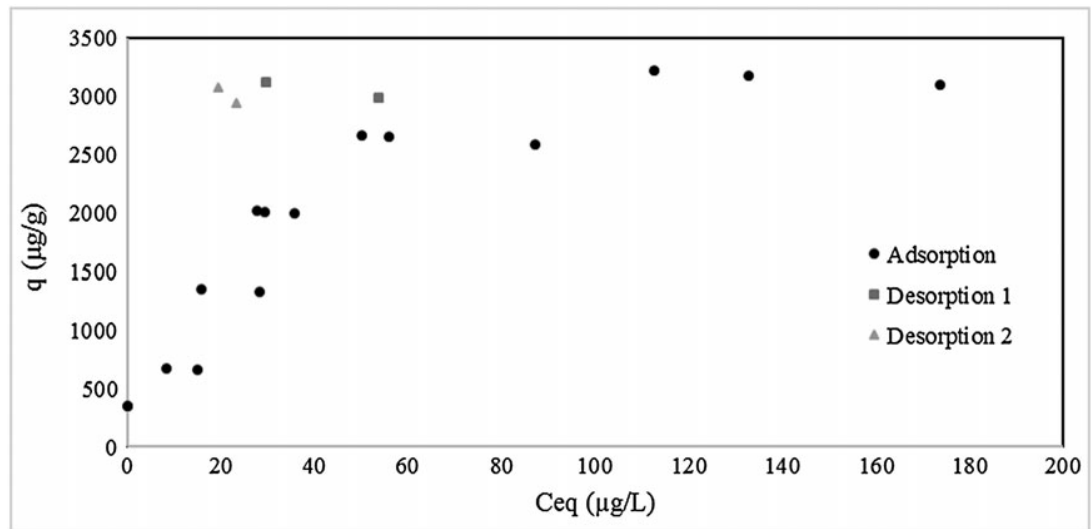


Batch desorption assays showing AC without ability to linalool desorption, on the other hand, cork presented at least three desorption isotherms.

So, cork granules, a residue of cork industry, have proven to be an excellent base material for a natural system for controlled release of linalool.

\section{ACKNOWLEDGEMENT}

This work received financial support from the European Union (FEDER funds through COMPETE) (Project NATURBEL - Ref. 30273) and National Funds (FCT, Fundação para a Ciência e aTecnologia) through Projects UID/QUI/50006/2013 and PTDC/AAG-TEC/2692/2012.

\section{REFERENCES}

1. Koulivand PH, Khaleghi Ghadiri M, Gorji A. Lavender and the Nervous System. Evidence-based Complement Altern Med. 2013. https://doi. org/10.1155/2013/681304

2. Erland LAE, Mahmoud SS. Essential Oils in Food Preservation, Flavor and Safety. Minnesota, USA: Elsevier; 2016.

3. Lillehei AS. Effect of lavender Aromatherapy via inhalation and Sleep hygiene on Sleep in college students with Self-reported Sleep issues, Dissertation For The Degree Of Doctor Of Philosophy. University Of Minnesota, 2014.

4. Zeng Q, Zhao J, Wang J, Zhang X, Jiang J. Comparative extraction processes, volatile compounds analysis and antioxidant activities of essential oils from Cirsium japonicum Fisch. ex DC and Cirsium setosum (Willd.) M.Bieb. LWT - Food Sci Technol. 2016;68:595-605.

5. Bickers D, Calow P, Greim H, et al. A toxicologic and dermatologic assessment of linalool and related esters when used as fragrance ingredients. Food Chem Toxicol. 2003;41:919-942.

6. Yang T, Zhu Y, Shao C-Y, et al. Enantiomeric analysis of linalool in teas using headspace solid-phasemicroextraction with chiral gas chromatography. Ind Crops Prod. 2016;83:17-23.

7. Sids O, U. Publications, Introduction Linalool Cas $N^{\circ}:$ 78-70-6, n.d.

8. Peana AT, D'Aquila PS, Panin F, Serra G, Pippia P, Moretti MDL. Antiinflammatory activity of linalool and linalyl acetate constituents of essential oils. Phytomedicine. 2002;9:721-726.

9. Kinninmonth MA, Liauw CM, Verran J, et al. Investigation into the suitability of layered silicates as adsorption media for essential oils using FTIR and GC-MS. Appl Clay Sci. 2013;83-84:415-425.

10. Cheng BH, Sheen LY, Chang ST. Evaluation of anxiolytic potency of essential oil and S-(p)-linalool from Cinnamomum osmophloeum ct. linalool leaves in mice. J. Tradit Complement Med. 2015;5:27-34.

11. Seidling JR, Wenzel SW, Ramshak DL, Van Himbergen TJ, Long-lasting fragrance delivery system US 8871705 B2, 2014.

12. Carvalho IT, Estevinho BN, Santos L. Application of microencapsulated essential oils in cosmetic and personal healthcare products-a review. Int J Cosmet Sci. 2016;38:109-119.

13. Ribeiro AJ, Lucena FR, Souza D, et al. Gums' based delivery systems: Review on cashew gum and its derivatives. Carbohydr Polym. 2016;147:188-200.

14. Souza MA, Oliveira JE, Medeiros ES, Glenn GM, Mattoso LHC. Controlled release of linalool using nanofibrous membranes of poly (lactic acid) obtained by electrospinning and solution blow spinning: A Comparative Study. J Nanosci Nanotechnol. 2015;15:5628-5636.

15. Davies DN, Pirrie AB, Coffee RA, AROMA DISPENSING DEVICE. US8074640, 2011.

16. SpectorD, SELF-STICKAROMA-DISPENSINGTAB. US4277024, 1981.

17. Jendrucko ML, Jendrucko PJ, AROMATHERAPY DELIVERY SYSTEM. US7427417, 2008.

18. Donnelly TE, Klett KA, Ebenezer AS, Kvantas R, DISPOSABLE SHEET FRAGRANCE DELIVERY SYSTEM. US6921024, 2005.
19. SilvaSP, a.SabinoM, FernandesEM, CorreloVM, BoeselLF, Reis RL. Cork: properties, capabilities and applications. Int Mater Rev. 2005;50:345-365.

20. Lequin S, Chassagne D, Karbowiak T, Gougeon R, Brachais L, Bellat JP. Adsorption Equilibria of Water Vapor on Cork. J Agric Food Chem. 2010;58:3438-3445.

21. Domingues VF, Priolo G, Alves AC, Cabral MF, Delerue-Matos C Adsorption behavior of alpha -cypermethrin on cork and activated carbon. J Environ Sci Health B. 2007;42:649-654.

22. Domingues V, Alves A, Cabral M, Delerue-Matos C. Sorption behaviour of bifenthrin on cork. J Chromatogr A. 2005;1069:127-132.

23. Yahya MA, Al-Qodah Z, Ngah CWZ. Agricultural bio-waste materials as potential sustainable precursors used for activated carbon production: A review. Renew Sustain Energy Rev. 2015;46:218-235.

24. Yakout SM, Sharaf El-Deen G. Characterization of activated carbon prepared by phosphoric acid activation of olive stones. Arab J Chem. 2012. https://doi.org/10.1016/j.arabjc.2011.12.002

25. Suhas, Carrott PJM, Ribeiro Carrott MML. Lignin-from natural adsorbent to activated carbon: A review. Bioresour Technol. 2007;98:2301-2312.

26. Saeidnia S, Gohari AR, Haddadi A, Amin G, Nikan M, Hadjiakhoondi A. Presence of monoterpene synthase in four Labiatae species and Solid-Phase Microextraction-Gas chromatography-Mass Spectroscopy analysis of their aroma profiles. Pharm Res. 2014;6:138-142.

27. Dawidowicz AL, Szewczyk J, Dybowski MP. Modified application of HS-SPME for quality evaluation of essential oil plant materials. Talanta. 2016;146:195-202.

28. Moreira N, Lopes P, Cabral M, Guedes de Pinho P. HS-SPME/GC-MS methodologies for the analysis of volatile compounds in cork material. Eur Food Res Technol. 2016;242:457-466.

29. Vas G, Vékey K. Solid-phase microextraction: A powerful sample preparation tool prior to mass spectrometric analysis. J Mass Spectrom. 2004;39:233-254.

30. SANCO/10684/2009(01/01/2010), 2009.

31. Lowell S, Shields JE. Powder Surface Area and Porosity. Dordrecht: Springer Netherlands; 1984.

32. Donohue M, Johns Hopkins Univ. Chem. Eng. n.d.

33. Srivastava S, Goyal P. Novel Biomaterials. Berlin, Heidelberg: Springer Berlin Heidelberg; 2010.

34. Miz MEL, Salhi S, Bachiri AEL, Wathelet JP, Tahani A. Adsorption of essential oil components of Lavandula angustifolia on sodium modified bentonite from Nador. African J Biotechnol. 2014;13:3413-3425.

35. Reverchon E. Supercritical desorption of limonene and linalool from silica gel: Experiments and modelling. Chem Eng Sci. 1997;52:1019-1027.

36. Fonseca AL, Brazinha C, Pereira H, Crespo JG, Teodoro OMND. Permeability of cork for water and ethanol. I Agric Food Chem. 2013;61:9672-9679.

37. Me R, Ma F. Water absorption by cork. Wood Fiber Sci. 1993;25:339-348.

38. de B. Fernandes RV, Botrel DA, Silva EK, et al. Cashew gum and inulin: New alternative for ginger essential oil microencapsulation. Carbohydr Polym. 2016;153:133-142.

39. Singh B, Sharma N. Modification of sterculia gum with methacrylic acid to prepare a novel drug delivery system. Int I Biol Macromol. 2008:43:142-150.

40. Ud-Daula AFMS, Demirci F, Abu Salim K, et al. Chemical composition, antioxidant and antimicrobial activities of essential oils from leaves, aerial stems, basal stems, and rhizomes of Etlingera fimbriobracteata (K.Schum.) R.M.Sm. Ind. Crops Prod. 2016;84:189-198. 